\title{
Corol·lari
}

\section{Les relacions laborals: un espai per a la professionalització}

\author{
M. Jesús Espuny Tomás
}

Universitat Autònoma de Barcelona. Diplomatura de Relacions Laborals 08193 Bellaterra (Barcelona). Spain

\section{Resum}

Els trets que caracteritzen la diplomatura de Relacions Laborals a la U niversitat Autònoma de Barcelona són la interdisciplinareitat i les pràctiques integrades, sempre externes, que ofereixen al estudiant una primera aproximació a la realitat laboral, al mateix temps que dóna a conèixer la titulació als múltiples sectors professionals relacionats amb aquests estudis.

Paraules clau: titulacions, primer cicle, recursos humans, graduat social.

Abstract. Industrial relations: a place for the professionalism

The main characteristics of the Graduate Industriale Relation Studies at the U niversitat Autònoma de Barcelona are the various disciplines and integrated training, always outside the University, which allow students to have firs contact with the working world and, at the same time, let many professional sectors linked to this studies know these G raduate Studies.

Key words: degrees, first term, human resources, social graduated.

\section{Sumario}

1. Una titulació interdisciplinària en una facultat jurídica

2. Les pràctiques integrades
3. Un ventall de possibilitats per a una professió amb futur

4. L'objectiu: un segon cicle de Relacions Laborals, ja! 


\section{Una titulació interdisciplinària en una facultat jurídica}

El curs 1993-1994 varèm començar plegats un projecte: engegar a la Universitat Autònoma de Barcelona (UAB) una nova titulació de cicle mitjà que tenia un precedent històric immediat en els estudis de les escoles de graduats socials, i més concretament en el pla d'estudis de G raduat Social de 19801.

Dintre de la Facultat de $D$ ret es contemplava amb interès aquesta opció d'interdisciplinarietat que la diplomatura de Relacions L aborals oferia: els professors d'altres facultats i d'àrees de coneixement molt diverses impartirien docència en la nova titulació amb mètodes de treball diferents i utilitzant estratègies docents pròpies de les seves disciplines.

El compromís personal va ser superior a qual sevol objectiu, més o menys formalitzat en documents acadèmics, i va fer que professors i alumnes intentéssim reval oritzar el nostre esforç de forma conjunta. Algunes de les fites que hem anat aconseguint han quedat reflectides en les reunions semestrals, la participació dels estudiants en projectes com l'avaluació de la titulació dins del Plan $\mathrm{N}$ acional de Evaluación del Consejo de U niversidades o en la reforma del pla d'estudis de 1993. La col·laboració i la implicació de totes les àrees de coneixement en la millora de la qualitat de la docència a la diplomatura de Relacions Laborals ha donat com a resultat I'anàlisi conjunta dels programes i la interrelació entre les assignatures afins, a fi d'evitar la coincidència de matèries.

La petició i la concessió de nous equipaments audiovisuals ha permès poder gaudir de televisions i vídeos a totes les aules, la qual cosa ha millorat les possibilitats docents. Els professors han participat en les J ornadas $\mathrm{N}$ acionales sobre la Enseñanza en las Relaciones Laborales i han establert comunicacions amb altres docents de les diferents titulacions equivalents d'arreu de l'Estat. La activitat dels nostres alumnes de les tres promocions ha fet possible la seva integració en la Comisión Permanente Estatal de Estudiantes de Graduado Social y Relaciones Laborales i la Associació d'Antics Alumnes de Relacions Laborals de laUAB.

Q uines sortides professionals oferirem als nostres diplomats? Un díptic informava quasi telegràficament, seguint el text del BOE, de les possibilitats laborals: «En tractar-se d'estudis interdisciplinaris de les relacions de treball, aquesta diplomatura es caracteritza per la possibilitat de múltiples sortides professionals [... ]». A continuació citava diverses opcions, com la gestió de recursos humans a les administracions públiques i a les empreses públiques i privades, l'assessorament general extern o la investigació en la teoria de les relacions laborals, tant en l'àmbit acadèmic com en l'àmbit d'estudis més aplicats. El seu espai semblava ampli, quasi il-limitat en el camp laboral: senzillament, s'havia de demostrar que la formació rebuda s'adequava a les expectatives reals de l'entorn social i econòmic.

1. Ana M. Alfaro de Prado Sagrera; M iguel C. Rodríguez Piñero; J. Ignacio U galde GonzÁLez (1996). Los Estudios de Relaciones Laborales en España. Sevilla: Consejo General de Colegios $O$ ficiales de Graduados Sociales de España en colaboración con M utual Cyclops, p. 33-38. 


\section{Les pràctiques integrades}

\subsection{El pla d'estudis i el practicum}

Les pràctiques integrades eren una de les grans novetats del Reial $D$ ecret 1429/1990 que preveia un practicum o bloc de pràctiques integrades que havien de cursar tots els estudiants. Es tractava d'una matèria troncal, exclusivament de pràctiques, totalment independent dels crèdits assignats a les diferents matè ries. Corresponia al practicum que també figurava en altres titulacions oficials. $M$ algrat això, les pràctiques en empreses estaven ja previstes al Reial D ecret 1497/81 referent a programes de cooperació educativa que va establir el marc legal per a la participació de les empreses en la formació universitària².

La universitat té la necessitat de relacionar-se amb la societat a la qual serveix. Aquest aspecte ha millorat en els darrers anys. «N o hi ha dubte que si, d'una banda, la major part dels universitaris ha renunciat a un altiu aillament en la seva torre de marfil, de l'altra, la immensa majoria de les persones 0 entitats de la nostra societat civil són més conscients de la necessitat de col'laborar amb la universitat, tant des del punt de vista de la formació i del reciclatge dels seus professionals com des de la recerca i l'assessorament»?.

Els coneixements que els alumnes reben són excessivament teòricsi han de formar-se en el treball pràctic que desenvoluparan en un futur com a professionals; aquest era l'objectiu del practicum, pràctiques externes o qualsevol altra matèria que dins els nous plans d'estudis es plantegen com una incursió, potser la primera, dins d'un camp estrictament vinculat als seus estudis; podria també plantejar-se com una matèria pràctica més dins les aules ${ }^{4}$.

\subsection{El plantejament de les pràctiques integrades de la diplomatura de Relacions Laborals a la U AB}

L'opció de les pràctiques integrades de la diplomatura de R elacions Laborals que es va potenciar des de la Facultat de D ret de la U AB des de la primera promoció, no era gens fàcil: I'accés de l'alumne a la realitat laboral «autèntica» per la qual s'està formant i l'establiment d'uns vincles entre la U AB i les entitats col-laboradores per mitjà dels tutors que ajuden de forma decisiva en la marxa de la titulació: comentant els punts als quals hem de donar més importància en les classes teòriques perquè són aspectes que troben en el món professional

2. Ana M. Alfaro i altres. Los estudios de Relaciones Laborales.. , cit., p. 48-49; AA.DD . Las prácticas externas. Ponencia y comunicaciones presentadas en el XXX Congreso Estatal de estudiantes de Graduado Social/Relaciones Laborales, Saragossa, març de 1995.

3. Josep LAPO RTE i SALAS. La Universitat catalana. Una reflexió històrica. Lliçó inaugural del curs acadèmic 1995-1996 a la UAB, p. 18.

4. Consejo de U niversidades. Secretaría General (1991). Lasprácticas en la empresa en la formación universitaria. M adrid: Consejo de U niversidades-Fundación U niversidadEmpresa. Aquesta publicació ofereix les C onferencies i C omunicacions desenvolupades en el XVII Seminario Universidad-Empresa (1-2 d'octubre de 1990). 
o valorant les actituds més o menys receptives dels estudiants i la seva integració a l'entorn laboral on realitzen les pràctiques 5 .

L'objectiu de les pràctiques era doble: d'una banda, i en general, intentar capacitar professionalment els alumnes complementant les matèries teòriques. D 'una al tra, valorar la introducció de la titulació en el mercat laboral ampliant les possibles sortides professionals. Indirectament, es donava resposta a les inquietuts que en al tres àmbits havien manifestat els al umnes6.

Els centres d'atenció de la titulació eren, segons les directrius generals, la gestió de personal i el règim juridicolaboral. Es va intentar presentar una oferta que omplís les expectatives dels estudiants. Es desitjava que tots sortissin de les aules per a realitzar una estada de cent vint hores en una entitat col·laboradora, gestionada per la Facultat de D ret.

L'adequació de les estructures administratives ha estat fonamental en aquest procés, que suposa una activitat contínua de gestió. A tot això s'afegeix l'aprenentatge necessari que s'ha hagut d'assumir, les eventual itats que sorgeixen per les dues parts, a vegades difícils de preveure i que s'han de solucionar ràpidament, o l'increment de les places, que van passar a ser trenta-nou per a la primera promoció (1993-1996) a cent quaranta-quatre per a la tercera en el curs 1997-1998, amb una oferta real de cent setanta llocs7.

\section{Un ventall de possibilitats per a una professió amb futur}

D otar d'unes característiques autèntiques d'interdisciplinarietat els estudis de diplomat de Relacions Laborals de la UAB ha estat l'eix per oferir un seguit de sortides professionals, confirmades per la diversitat d'entitats que col'laboren en les pràctiques integrades.

L'Administració pública era un camp molt atractiu - afirmació pendent de la nova llei de la funció pública - pels futurs graduats. Els estudiants que han realitzat les pràctiques integrades han descobert un magnífic lloc on la realitat supera tot el que esperaven: semblava que l'únic destí era el possible accés als departaments de recursos humans o de personal. La creació d'observatoris laborals o d'oficines d'orientació laboral ha permès ampliar les sortides professionals dels nostres alumnes, en dotar d'una gran activitat petits municipis

5. M. JesúsESPUNY T OM Ás; N úria G ALLEGo G On ZÁLEZ. «Las prácticas integradas en el plan de estudios de Relaciones Laborales: notas sobre una experiencia». Comunicació presentada a las III Jornadas N acionales sobre la enseñanza en las R elaciones Laborales celebrades a la Universitat Rovira i Virgili a octubre de 1998.

6. M. Lluïsa FABRA; M iquel DOM ĖNECH (1995). Els relats del'alumnat: deixar parlar i escoltar. Bellaterra: UAB, p. 32-39.

7. Consell Social. Universitat Autònoma de Barcelona (1989). Universitat complexa. U niversitat acomplexada. Un estudi sobre la percepció social del sistema universitari. Bellaterra: UAB, p. 69-85. «Universitat i Societat»; Consell Comarcal del Vallès O ccidental. Guia de serveis universitaris adreçats a les empreses, curs 1995-1996, coordinat per les cambres oficials de comerç i indústria de Sabadell i Terrassa, i amb el suport de la CTT, el campus de la UPC de Terrassa i I'O ficina d'Investigació de la UAB. 
amb grans polígons industrials, on la taxa d'atur és molt baixa i la inserció laboral és molt alta i cal gent preparada per a la gestió.

L'auditoria laboral, encara pendent de generalització, és també una nova especialització que possibilita els diplomats de Relacions L aborals per accedir a un espai pràcticament nou a casa nostra. L'auditoria laboral requereix una formació tècnica per poder emetre un dictamen sobre temes com: les polítiques de personal, la planificació i el desenvolupament dels recursos humans, la política d'organització del treball, etc., una tasca específica del graduat social 0 del diplomat de Relacions Laborals.

El diplomat de Relacions Laborals, en donar-se d'alta al C ol·legi $O$ ficial de G raduats Socials, es converteix en graduat social. La magnífica relació amb I'Il|lustre Col·legi de Barcelona i el suport que sempre hem rebut ha permés que els nostres al umnes poguessin accedir a despatxos professionals de col l legiats on han conegut la intensitat i la extensió dels serveis que presten.

Les associacions empresarials i les empreses de tots els sectors permeten també al diplomat de Relacions Laborals una sortida professional d'acord amb els estudis cursats. L'administració de personal i la selecció i la formació són camps extensos on es poden desenvolupar tasques relacionades amb els temes que són el centre d'atenció de la titulació: la gestió de personal i el règim juridicolaboral. La implantació de la Llei de prevenció de riscos laborals a les empreses és una tasca on poden col·laborar, i amb eficàcia, els diplomats de Relacions Laborals.

Els gabinets jurídics dels sindicats són els centres neuràl gics d'una intensa activitat laboral. Els seus professionals són també magnífics tutors que saben transmetre les inquietuds i els coneixements en un ambient extraordinari de col·laboració i ajuda.

Finalment, les mútues d'accidents de treball i malalties professionals ofereixen moltes sortides. La seva intervenció en I'aplicació de la Llei de prevenció de riscos laborals, les seves relacions amb la Seguretat Social, la gestió dels accidents de treball... suposen una important sortida professional que caldria refermar amb l'obtenció d'un diploma homologat de tècnic en riscos laborals, d'acord amb les exigències de la nova legislació.

\section{L'objectiu: un segon cicle de Relacions Laborals, ja!}

Una pancarta identifica a la U AB l'edifici on s'imparteix la docència de la diplomatura de Relacions Laborals. A vegades el vent la fa volar i durant uns quants dies no la podem veure. Fa dos anys que està penjada i és visible des de molts llocs del campus de Bellaterra. La frase és visible concloent: Segon cicle de Relacions Laborals, ja!

El 7 de juliol de 1994 es va fer una primera reunió de responsables de les diplomatures de Relacions Laborals de l'Estat a la U niversitat Pompeu Fabra. D es d'aleshores s'està seguint un Ilarg camí perquè els diplomats de Relacions Laborals puguin accedir a un segon cicle, gaudir d'una titulació superior que els permetés accedir a uns al tres llocs de treball als quals ara no poden accedir 
i presentar-se a oposicions que els estan vetades. La diplomatura, en tot cas, no desapareixeria.

El diplomat de Relacions Laborals no pot accedir al segon cicle de cap titulació i ha de començar de nou, a primer, una segona opció universitària. Una greu mancança que constitueix un greuge comparatiu davant d'altres estudis.

El curs 1998-1999 farà cinc anys que la diplomatura de Relacions Laborals va començar a impartir-se al campus de Bellaterra. Una petita gran titulació de la qual tots estem satisfets. 